\title{
Résumé of the 1996 Annual General Meeting held during the Annual Scientific Meeting of the International Medical Society of Paraplegia in Atlanta, Georgia, USA
}

\section{The President's Report}

Dr Paul Dollfus, President of IMSOP, reported on the conditions of affiliation for societies who wished to affiliate with IMSOP: a society which shared the aims of IMSOP and had a minimum of 100 members, could be considered for affiliation up to a maximum of 12 societies. He reminded the AGM that affiliation was free of charge and that the representative on Council of an affiliated society also had to be a full member of IMSOP. He welcomed the representatives from the affilitated societies who were attending this meeting.

He hoped that the collaboration between all the societies would be useful and looked forward to receiving information on future meetings etc. from the affiliated societies. New members would be welcome to join IMSOP from these societies.

As an 'international scientific umbrella organisation' IMSOP has an obligation to inform the affiliated societies about latest scientific developments and to coordinate activities concerning ongoing research and the management of people with spinal cord lesions as well as to pursue its concern with the prevention of trauma and disease. Regional and national societies should open their meetings to the medical as well as the allied professions in their regions aiming to reduce the imbalance between the developing (representing two thirds of the global population) and the so-called developed countries.

The President thanked various members and organisations for their contributions to the life of the society.

Dr Dollfus welcomed Dr Hans Frankel as the 9th President of IMSOP and wished him all the best.

\section{The Honorary Secretary's Report}

Professor Jean-Jacques Wyndaele announced that the Society would soon be communicating by E-Mail which would improve and speed communications as well as bring down the cost.

The deaths of Dr Estin Comarr (USA), Dr Murray Freed (USA), Dr Lars Sullivan (Sweden), Dr Christopher Gard (Sweden), Dr A Hardy (UK), Dr Terry McSweeney (UK) and Dr Gustave Gingras (Canada) were announced.

The total membership of the Society now stood at 1158 .

The affiliation of ASIA (American Spinal Injury
Association), NVPD (Dutch-Flemish Society of Paraplegia and DMGP (German Speaking Medical Society of Paraplegia) was approved by the AGM.

An up-to-date list of the membership of IMSOP would be available before the end of 1996 and would be mailed to the members.

\section{The Honorary Treasurer's Report}

Mr Isaac Nuseibeh presented the Society's financial report on behalf of $\mathrm{Mr}$ Wagih El-Masry, Honorary Treasurer and stated that the balances at 31 December 1995 looked quite healthy.

The members fully sponsored and partially sponsored by the Swiss Interdevelopment Fund (SF) of IMSOP were mentioned.

Members should inform prospective members in regions where the support from the Swiss Fund would be needed of the availability of such help.

\section{Editor's Report}

Mr Phillip Harris, the Editor, confirmed that Spinal Cord, the new title of the Society's scientific journal formerly known as Paraplegia had been well received.

The death of Dr Lars Sullivan (Sweden) who was an assistant Editor, was a great loss to the journal. Dr Douglas Brown (Australia) replaces him as Assistant Editor and Dr Paul Dollfus has accepted to be an Assistant Editor.

The Japanese regional issue of the journal was published in July 1996, the further regional issues (French, USA and German) are in preparation.

A new promotional brochure for Spinal Cord is now available and should be widely distributed by members of the Society to be available for participants at Meetings, Conferences etc on topics relevant to spinal cord injury or disease.

The closing date for submission of entries for the Paraplegia Prize has been extended to 31 March 1997.

Members are requested to send all information available on scientific meetings, new appointments, distinctions, honours etc in their regions directly to the Secretariat at Stoke Mandeville Hospital.

$\mathrm{Mr}$ Harris is seeking new referees to peer review manuscripts on the following topics:-

Epidemiology; Ergonomics; Ethics; Medical Neurol- 
ogy; Psychiatry; Psychology; Statistics; Microbiology; Paediatric Neurosurgery; Paediatric Medical Neurology; Endocrinology; Neuropharmacology; Nutrition.

As was proposed and accepted by the Annual General Meeting of our Society in New Delhi last year, an excellent idea by Dr Bill Donovan from Houston, Texas is proceeding satisfactorily so that there will be a monthly Clinical Discussion Presentation on particular aspects of spinal cord injury and disease.

It is proposed to introduce another new feature for our journal in the form of Profiles of some of the Spinal Cord Services, Departments and Centres and along with this it is hoped to be able to develop a World Directory of such facilities.

There is scope for further contributions from authors on non-traumatic spinal paralysis, ie spinal cord disease in relation to the epidemiology prevention and management. Leading articles on these topics would be welcome.

\section{7th Annual Scientific Meeting, Sao Paulo, Brazil: 18-20 June 1998}

English will be the official language of all platform presentations. However, translations into Spanish and Portugese would be available for local delegates.

Topics proposed for 1988 :

1. Penetrating Injuries of the Spinal Cord

2. Indications for Surgical and non-Surgical Treatment of Closed Spinal Cord Injuries

3. Pressure Sores including Social and PsychoSocial Causes and Effects

4. Early Bladder Rehabilitation

5. Osteoporosis in Spinal Cord Injury

38th Annual Scientific Meeting, Copenhagen, Denmark, 18-20 June 1999

1. Circulatory Control and Metabolic Disturbances in Spinal Cord Injury

2. Sexuality and Fertility

3. Heterotopic Ossification (Para-articular Classification)
One or two additional topics will complete this list later.

\section{9th Annual Scientific Meeting, Sydney, Australia 20-22 October 2000}

\section{The Constitution}

The new Constitution and Bye-Laws of the International Medical Society of Paraplegia was approved. On 1st January 1997 all the assets and liabilities of IMSOP will be transferred to a company limited by guarantee of the same name and with similar objects to that of the society.

\section{Proposals for Senior and Emeritus membership}

The following retired members were elected to Senior membership of the Society

Dr EM da Fonseca, Portugal

Dr U Phiphobmongkol, Thailand

Dr JA Engelbrecht, South Africa

Dr W Cook, USA

Dr E Stauffer, USA

Emeritus Member

Dr AC Pinkerton was elected an Emeritus member of IMSOP.

\section{The Society Medal - 1996 Award}

Dr Guido Zäch (Switzerland) has been awarded the Society Medal for 1996 by a majority vote of the Society Medal holders. He was a founder member of the Swiss Paraplegic Foundation and was held in high regard for his work in spinal cord injury. He has had six papers published to date.

\section{Conclusion}

The Annual General Meeting approved unanimously a vote of thanks to Dr Paul Dollfus who was chairing his last Annual General Meeting as President of IMSOP. 